\title{
Retinoid receptors and binding proteins
}

\author{
DAVID LOHNES, ANDRÉE DIERICH, NORBERT GHYSELINCK, PHILLIPE KASTNER, CARMEN LAMPRON, \\ MARIANNE LEMEUR, THOMAS LUFKIN, CATHY MENDELSOHN, HARI NAKSHATRI \\ and PIERRE CHAMBON
}

Laboratoire de Génétique Moléculaire des Eucaryotes du CNRS, Unité 184 de Biologie Moléculaire et de Génie Génétique de L'INSERM, Institut de Chimie Biologique, Faculté de Médecine, 11, rue Humann-67085 Strasbourg-Cedex, France

\section{Summary}

Retinoids, in particular all-trans retinoic acid (T-RA), are essential for normal development and homeostasis of vertebrates. Although many effects of retinoids, particularily with regard to teratogenicity, have been described in the literature, the mechanisms by which these simple signalling molecules work has only recently begun to be elucidated. We now recognize at least two classes of retinoid-binding proteins and two families of retinoid receptors. The ultimate interpretation of the retinoid signal within a given cell is probably the result of a complex series of interactions between these proteins, yet little is understood concerning the role each member of this signalling pathway plays. It is therefore imperative to dissect the molecular mechanisms which transduce the effects of these ligands, both in vivo and in isolated systems. One approach we are employing is gene targeting of retinoic acid receptors (RARs) and cellular retinoid-binding proteins to generate mice in which one or more of these genes has been functionally inactivated.

Key words: retinoic acid receptors, retinoid $\mathrm{X}$ receptors, cellular retinol-binding protein, cellular retinoic acid-binding protein, gene targeting.

\section{Introduction}

The term retinoid refers to any synthetic or natural compound which possesses vitamin A-like activity. At least three naturally occurring, biologically active, retinoids have been found which may regulate growth, differentiation and homeostasis of the developing vertebrate: all-trans retinoic acid (T-RA), 9-cis retinoic acid (9C-RA; Levin et al., 1992; Heyman et al., 1992) and 3,4-didehydroretinoic acid (ddRA; Thaller and Eichle, 1990). It has been proposed that retinoids may be natural morphogens (Maden, 1982, 1985; Tickle et al., 1982; Chytil, 1984; Slack, 1987; Thaller and Eichele, 1987; Smith et al., 1989; Eichele, 1989a,b; Brockes, 1989, 1990), although this viewpoint has been challenged recently by a number of reports which question the validity of T-RA as a true morphogen (Brockes, 1991; Wanek et al., 1991; Noji et al., 1991). However, the effects of ectopically administered T-RA, either during development (and in the adult) of several vertebrates or on cells in culture, have often been correlated with alterations in patterns of expression and/or the level of expression of specific genes (eg. Wang and Gudas, 1983; LaRosa and Gudas, 1988; Murphy et al., 1988; Chytil and Haq, 1990; Wang et al., 1990; Nicholson et al., 1990; Simeone et al., 1990; Kessel and Gruss, 1991; Izpisua-Belmonte et al., 1991). These observations strongly suggest that T-RA, in conjunction with its receptor (discussed below), may directly regulate gene expression which would ultimately interpret this putative morphogenetic signal. Alternatively, T-RA may act during development to regulate the expression of other factors which themselves may be true morphogens.

To date, two general classes of retinoid-binding proteins have been implicated in the retinoid signalling pathway. First, the cellular retinoid-binding proteins which include cellular retinol-binding proteins (CRBPs) I and II (see Blomhoff et al., 1991, for review) and cellular retinoic acidbinding proteins (CRABPs) I and II (Blomhoff et al., 1990; Giguère et al., 1990a). These proteins bind their ligands (retinol and T-RA, respectively) with high affinity and specificity. The precise function of these proteins is presently unknown, but it has been speculated that they play a role in retinoid metabolism and in the regulation of free retinoid concentration (see below).

The second class of retinoid-binding proteins consists of the products of two multigene families: the retinoic acid receptors $(\operatorname{RAR} \alpha, \beta$ and $\gamma$; for review, see Chambon et al., $1991)$ and the retinoid $X$ receptors ( $\mathrm{RXR} \alpha, \beta$ and $\gamma$; Hamada et al., 1989; Mangelsdorf et al., 1990, 1992; Rowe et al., 1991; Blumberg et al., 1992; Leid et al., 1992). Both classes of receptors are ligand-inducible, trans-regulators belonging to the nuclear receptor multigene family, which includes receptors for steroid hormones, thyroid hormones and vitamin D3 (Evans, 1988; Green and Chambon, 1988; Beato, 1989; Moore, 1990). RARs can be efficiently activated by either T-RA or 9C-RA at $50 \mathrm{nM}$ concentrations of either ligand. RXRs, on the other hand, are activated efficiently 


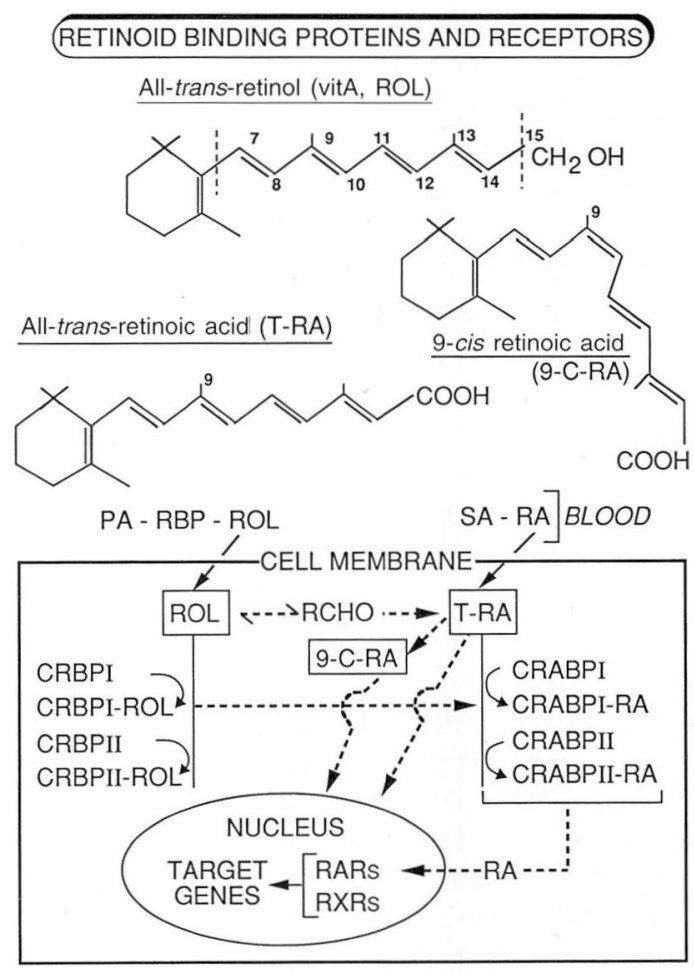

Fig. 1. Schematic representation of the components of the retinoid-signalling pathway. CRBP, cellular retinol-binding protein; CRABP, cellular retinoic acid-binding protein; RBP, retinol-binding protein; RAR, retinoic acid receptor; RXR, retinoid $\mathrm{X}$ receptor.

only by $9 \mathrm{C}-\mathrm{RA}$ in this concentration range. RXRs can, however, be activated by T-RA at high concentrations $(1 \mu \mathrm{M}$ or greater), probably through cellular conversion of T-RA to the 9-cis isomer (Heyman et al., 1992; Levin et al., 1992). Thus, with respect to transactivation via RXRs, T-RA could be considered as a prohormone, possibly converted to the 9-cis isomer in either a localized or systemic fashion.

The major components of the retinoid-signalling network discussed above are represented schematically in Fig. 1. To investigate how these proteins function ultimately to regulate diverse processes such as those involved in morphogenesis and homeostasis in vertebrates will require efforts along many different experimental avenues. One approach consists of disrupting the corresponding genes in the mouse via gene targeting (see Capecchi, 1989, for a review of this technique). Our objective is to generate animal models in which the genes encoding a specific retinoid-binding protein or retinoid receptor (or a specific isoform of a retinoid receptor - see below) has been functionally inactivated. These mouse models should provide useful tools for investigating the role that each of these proteins plays in transduction of the retinoid signal. Before describing the details of our gene targeting experiments, a review of retinoid-binding proteins and retinoid receptors will first be presented.

\section{Cellular retinoid-binding proteins}

The two classes of cellular retinoid-binding proteins
(CRBPI and II; CRABPI and II), while not directly implicated in transduction of the retinoid signal, probably play important roles in the ultimate response of a given cell type to retinoids.

CRBPs may play a role in the storage and metabolism of retinol, itself a precursor to T-RA (Blomhoff et al., 1990). CRBPI has been suggested to regulate the formation of the major storage form of retinol, retinly esters (Ong et al., 1987), whereas CRBPII may mediate intracellular transport of retinol during the adsorption of this compound from the intestinal lumen (Ong, 1987; Ong et al., 1987). In addition, transcripts encoding CRBPI are T-RA-inducible (Levin et al., 1987; Smith et al., 1991), which may represent an in vivo feedback mechanism which ultimately regulates the amount of retinol available for conversion to TRA. The restricted spatio-temporal expression pattern of these two genes during mouse development and in the adult also suggests tissue-specific functions (Dollé et al., 1989; Ruberte et al., 1991).

CRABPI and II bind T-RA with high, although slightly different, affinities (Blomhoff et al., 1990, 1991; Giguère et al., 1990a; Stoner and Gudas, 1989). Again, the precise function that these two proteins fulfil is, at present, unknown. It has been speculated that they may be necessary for transport of T-RA to the nucleus, where it may be transferred to one of the RARs (Takase et al., 1979, 1986). Alternatively, CRABPs have been suggested to control the actual intracellular concentration of free RA within a given cell (Maden et al., 1988; Smith et al., 1989; Ruberte et al., 1991). CRABPII, like CRBPI, is inducible by retinoic acid (Wei et al., 1989; Giguère et al., 1990a; Durand et al., 1992), perhaps providing a feedback mechanism whereby excess ligand could be sequestered, thus preventing inappropriate expression of RA-responsive genes. It is clear that the presence of these proteins is not obligatory for a cellular response to T-RA, as numerous retinoid-responsive cell lines have been documented which contain no detectible CRABPs.

\section{Retinoic acid receptors and retinoid $X$ receptors}

Three homologous RARs have been discovered in our laboratory and in others: RAR $\alpha$ (Petkovich et al., 1987; Giguère et al., 1987), RAR $\beta$ (de Thé et al., 1987; Brand et al., 1988; Benbrook et al., 1988) and RAR $\gamma$ (Zelent et al., 1989; Krust et al., 1989; Ishikawa et al., 1990). These genes map to different chromosomes in both mouse (chromosome 11, 14 and 15 for $\alpha, \beta$ and $\gamma$ respectively) and human (chromosome 17, 3 and 12 respectively; Mattei et al., 1991). Homologues for all three receptors have also been found in amphibians (Ragsdale et al., 1989; Giguère et al., 1989; Ragsdale and Brockes, 1991) and in chicken (Smith and Eichele, 1991), suggesting that these three genes have been conserved throughout the evolution of higher vertebrates.

More recent work has shown that the RXR family, composed of three subtypes $(\alpha, \beta$ and $\gamma$ ), is also conserved across species (Leid et al., 1992; Mangelsdorf et al., 1992 and references therein). It is interesting to note that a Drosophila homologue, ultraspiracle, has been documented 
for RXRs (Oro et al., 1990), indicating that this gene family may be more ancestral than the RARs.

Although the discovery of the RXR family with a unique and specific ligand (see above) suggested initially a divergent retinoid-signalling pathway, recent results indicate that the RAR and RXR families may, in fact, represent convergent signalling pathways. This observation comes from several groups which have shown that, at least in vitro, RAR/RXR heterodimers form both in solution and on certain RAREs (retinoic acid response elements), and that this complex transactivates T-RA responsive promoters much more efficiently than homodimers of either receptor ( $\mathrm{Yu}$ et al., 1991; Kliewer et al., 1992; Leid et al., 1992; Zhang et al., 1992; Durand et al., 1992). Thus, if one argues that these heterodimers function in an analogous manner in vivo, the pleiotropic effects of retinoids may be explained, at least in part, by the multitude of combinatorial possibilities between these two receptor types and the availability of each specific ligand.

\section{Sequence comparison of the retinoic acid receptors}

RARs, like all members of the nuclear receptor superfamily, have a modular structure consisting of six regions designated A-F (Green and Chambon, 1988). Previous reseach has shown that region $\mathrm{C}$ represents the DNA-binding domain, via folding into a zinc-stabilized structure. This domain also represents the most highly conserved region of this receptor family (Evans, 1988; Green and Chambon, 1988). The E region represents the ligand-binding domain whereas both the A/B and E regions of several steroid hormone receptors have been shown to harbour distinct transactivation domains which may operate in both a cell type and promoter-specific manner (Webster et al., 1988; Bocquel et al., 1989; Tora et al., 1989).

When RARs are compared across species, the amino acid sequences are highly conserved (eg. mouse and human; Krust et al., 1989; Zelent et al., 1989; Fig. 2). However, comparison of the three receptor subtypes within a given species reveals that only regions $\mathrm{B}, \mathrm{C}$ and $\mathrm{E}$ are highly conserved. This observation implies that each RAR may be functionally distinct, possibly regulating a subset of retinoid-responsive genes in a cell-type and/or promotordependent fashion. This is further substantiated by the finding of separate spatio-temporal expression patterns for the RARs during embyronic development (see below).

\section{Retinoic acid receptor isoforms}

The discovery of isoforms for all mouse RAR (mRAR) types adds an additional level of complexity to RAR expression. To date two main isoforms have been discovered for mRAR $\alpha$ (Leroy et al., 1991a), four for mRAR $\beta$ (Zelent et al., 1991; Nagpal et al., 1992a) and two for mRAR $\gamma$ (Kastner et al., 1990; Giguère et al., 1990b; Fig. 3 ). The structure of these isoforms shares a common motif; for any RAR type, each isoform diverges only in the $5^{\prime}$ untranslated and $\mathrm{A}$ region. The sequence from the $\mathrm{B}$ region

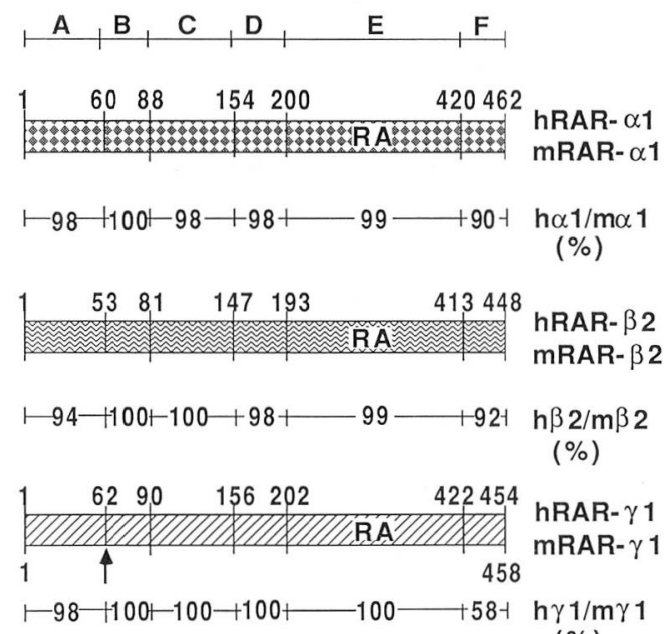

(\%)

Fig. 2. Comparison of amino acid sequence homology between human and mouse RAR subtypes. The amino acid residue number corresponding to the boundary of each region is given at the top, and percent sequence homology comparison between human and mouse receptors given at the bottom.

to the $3^{\prime}$-untranslated sequence remains identical. In the mouse these isoforms are expressed under the control of at least two independent promoters, and result from differential splicing (Kastner et al., 1990; Brand et al., 1990; Leroy et al., 1991a; Zelent et al., 1991; see Fig. 3). It is interesting to note that the isoforms mRAR $\alpha 2$ and all mRAR $\beta$ transcripts are induced by T-RA, suggesting yet another level of complexity in this gene network. Two of these genes, mRAR $\alpha 2$ and mRAR $\beta 2$, contain a similar RARE in their promoter regions which likely mediates the T-RA-induced expression of these genes (de Thé et al., 1990; Sucov et al., 1990; Leroy et al., 1991b). Recently, a divergent RARE has been described for RAR $\gamma 2$ (Lehmann et al., 1992). The significance of the minor isoforms $\alpha 3$ to $\alpha 7$ and $\gamma 3$ to $\gamma 6$ is unclear (Kastner et al., 1990; Leroy et al., 1991a; Zelent et al., 1991).

As for RAR types, sequence comparisons of mouse and human RAR isoforms again reveals a striking level of homology across species (Kastner et al., 1990; Leroy et al., 1991a; Zelent et al., 1991). This sequence conservation is exhibited not only in the A region, but also extends to the $5^{\prime}$-untranslated region of each isoform, suggesting the retention of conserved mechanisms that may involve regulation of translation, mRNA stabilization or other events important for proper expression of these proteins.

As discussed above, transcription activating functions (AFs) have been ascribed previously to the $\mathrm{A} / \mathrm{B}$ and $\mathrm{E}$ regions of other members of the steroid hormone superfamily, such as the estrogen receptor. Thus, each mRAR isoform could differ in its transactivation capabilities at a given promoter via the difference in its A region. Indeed, recent work from our laboratory shows that the different RAR subtypes do indeed possess AFs in the E region, as well as different transcription modulation activities in the $\mathrm{A} / \mathrm{B}$ region that function in a promoter-dependent manner (Nagpal et al., 1992b). 

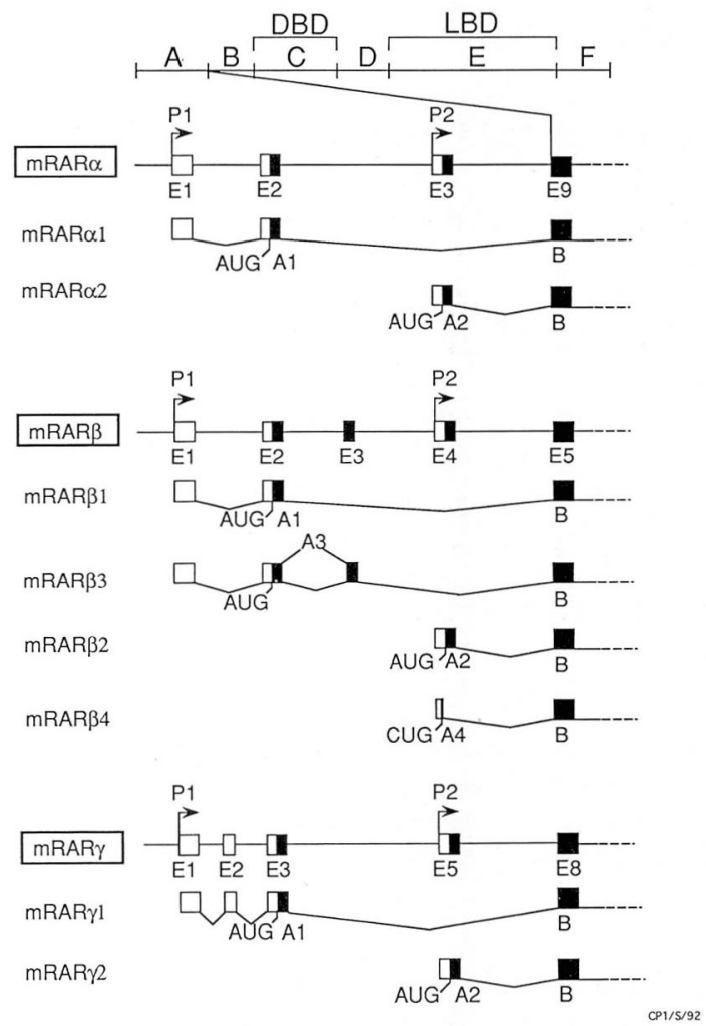

Fig. 3. Schematic representation of the $5^{\prime}$ region of the three mouse RAR genes and of their major isoforms. The exons (E) are indicated by boxes and are numbered as in Kastner et al. (1990), Leroy et al. (1991a) and Zelent et al. (1991). White boxes represent 5 -untranslated sequences and black boxes represent translated sequences. For a given RAR isoform, the numbering $\mathrm{A} 1, \mathrm{~A} 2, \mathrm{~A} 3$ and $\mathrm{B}$ represents the $\mathrm{A} 1, \mathrm{~A} 2, \mathrm{~A} 3$ and $\mathrm{B}$ regions of the receptor isoforms. For each receptor, $\mathrm{P} 1$ and $\mathrm{P} 2$ correspond to the upstream and downstream promoters, respectively.

\section{Mouse retinoic acid receptors and isoforms are differentially expressed during development}

Initial northern blot analysis (Petkovich et al., 1987; Krust et al., 1989; Zelent et al., 1989) and in situ analysis (Dollé et al., 1989, 1990; Ruberte et al., 1990, 1991) revealed a wide and differential pattern of expression for all three RARs in both the developing and adult mouse. Further northern blot analysis using probes specific for the major mRAR isoforms has shown additional evidence for isoform-specific expression. In summary, mRAR 1 expression has been found to be ubiquitous, which is in keeping with the structure of the promoter for this gene (Brand et al., 1990; Leroy et al., 1991a). The presence of this transcript in essentially all cell types may reflect a general requirement for retinoid-dependent gene regulation. In contrast, mRAR $\alpha 2$ has a more restricted pattern of expression, and this transcript is RA-inducible in embryonal carcinoma (EC) cell lines such as P19 and F9, consistent with the presence of a RARE in the promoter of this gene (Leroy et al., 1991b).

mRAR $\beta 1$ and $\beta 3$ transcripts are abundant in adult and embryonic brain, which may indicate a requirement for these isoforms in the development of the central nervous system (Zelent et al., 1991). As mentioned above, all three mRAR $\beta$ isoforms are RA-inducible in EC cells which is consistent with the presence of a functional RARE in the RAR 32 promotor (de Thé et al., 1990; Mendelsohn et al., 1991). A similar motif has not yet been identified in the promoter for the mRAR $\beta 1$ or $\beta 3$ genes.

mRAR $\gamma 1$ is expressed mainly in adult skin, whereas mRAR $\gamma 2$ transcripts are more abundant in early embryogenesis and in EC cells (Kastner et al., 1990). Previous in situ analysis indicates that RAR $\gamma$ may also play a role in chondrogenesis, as this gene is highly expressed in condensing precartilage during mouse embryogenesis (Dollé et al., 1989, 1990).

\section{Summary of the system}

As discussed above, the response of a given cell to retinoids will depend on a complex series of parameters, only some of which have been discussed here. It is clear that at least three endogenous retinoids may activate gene transcription (T-RA, 9C-RA and ddRA). The synthesis and distribution of these metabolites has not been fully elucidated, although this will surely be of great importance with regard to retinoid-dependent developmental processes. Cellular retinoid-binding proteins (CRBPI and II; CRABPI and II) are likely to play a pivotal role in regulating cellular responses to retinoids, possibly by controlling both the formation and concentration of free ligand capable of binding to nuclear receptors. Finally, at least eight major species of RARs ( 3 subtypes; 8 isoforms) and three species of RXRs (which may also be expressed as isoforms: Fleischhauer et al., 1992; Leid et al., 1992) have been documented. If one considers the possibility that these receptors may function in vivo as RAR:RXR heterodimers, through activation by two different ligands and possibly in a promoter and celltype specific fashion, it is clear that the combinatorial possibilities become considerable. This diversity through varied combinations may begin to explain the pleiotropic effects of retinoids in vivo. On the other hand, one may argue that this diversity may represent functional redundancy, a hypothesis currently impossible to refute with any direct evidence.

\section{Gene targeting of components of the RA-signal transduction network}

In order to determine which role(s) each of the above proteins may possibly play in development and homeostasis, we have begun gene targeting experiments, with the ultimate goal of establishing mouse lines in which each mRAR (or major mRAR isoform) or cellular retinoid-binding protein has been disrupted. This is being accomplished via homologous recombination in embryonic stem (ES) cells, as reviewed by Capecchi (1989). The results obtained from these experiments should provide valuable insight as to the specific roles these genes play during murine development and homeostasis of the mature animal. 


\section{Gene targeting of retinoid receptors and retinoid- binding proteins}

The methodology, cell lines and mouse strains used in our gene targeting experiments have been described in detail previously (Lufkin et al., 1991). Briefly, we use the ES cell line D3 (a kind gift from R. Kemler, Frieberg, Germany), cultured under standard conditions. Targeting constructs are generally of the replacement type (Capecchi, 1989), in which a neomycin resistance (neo) gene casette has been inserted into exonic sequences of an engineered genomic fragment. The purpose of the neo gene is twofold; firstly, it allows selection of integration events via cellular resistance to G418; secondly, it is used to disrupt the coding region of the targeted gene upon homologous recombination with the cognate ES cell allele. These constructs are linearised outside the region of homology to the target allele and used to electroporate D3 ES cells (usually $10^{7}$ cells/ electroporation). Selection for the expression of the neo gene is performed using $150 \mu \mathrm{g} / \mathrm{ml} \mathrm{G} 418$ for 12 days. In some experiments, negative selection against the expression of a HSV Tk gene (positive/negative selection; Capecchi, 1989) with $2 \mu \mathrm{M}$ gancyclovyr is also used. Surviving colonies are isolated, propagated and used for either PCR or genomic Southern blotting analysis to identify clones in which homologous recombination has occured. Cells from positive clones (10-20 cells) are then injected into 3.5-day mouse embryos (blastocysts) and the resulting embryos are reimplanted into pseudo-pregnant recipient females. Resulting male chimeras are then outbred with C57B1/6 females. Germ line transmission (passage of the injected ES cell genotype to the $F_{1}$ progeny) can be observed initially via the coat colour of the offspring. Pups carrying the mutation are identified by Southern blot analysis. Heterozygote animals are analyzed for phenotypic alterations and if viable and fertile are then inbred to obtain homozygote mutants for subsequent phenotypic analysis.

Gene targeting of the mRAR $\alpha 1$ locus will be used as a paradigm for disruption of other mRARs and retinoid-binding proteins. This isoform is the most ubiquitously expressed mRAR (as discussed above). As described previously, mRAR isoforms differ only in their 5'-untranslated and $\mathrm{A}$ regions. The strategy for disrupting a specific isoform, therefore, is to design a construct by which, after homologous recombination, the isoform will undergo premature termination in the A domain specific for that particular mRAR.

For the mRAR $\alpha$ locus, a number of genomic clones have been described previously (Leroy et al., 1991a). For homologous recombination, a suitable subclone was obtained which contained exon 2 of the mRAR $\alpha$ transcription unit. This exon is specific for mRAR $\alpha 1$, and contains a portion of its $5^{\prime}$-untranslated region and the entire A region of this gene. Using this genomic fragment, a construct was prepared in which a neo cassette was inserted into the open reading frame of this exon (see Fig. 4). Homologous recombination of this construct with the cognate ES cell allele should result in a null mutation for this isoform via premature termination of the gene product at stop codons located in the $5^{\prime}$ end of the neo casette (Fig. 4). In order to avoid possible alteration of expression levels of the mRAR $\alpha 2$ gene, which lies downstream of this locus, the neo casette used was driven by a minimal promoter, which consists only of the Rous sarcoma virus TATA box and lacks any viral enhancer sequences (derived from the neo casette p566 used by Lufkin et al., 1991). As depicted in Fig. 4, the close proximity of the $3^{\prime}$ end of the neo casette with respect to the $3^{\prime}$ boundary of the homologous recombination event should allow positive clones to be detected by a PCR reaction via amplification of a $1 \mathrm{~kb}$ product specific for the targeted allele.

As expected for a minimal promoter, a low number (22) of G418 resistant colonies were obtained using this targeting construct. PCR analysis of genomic DNA obtained from these clones, however, revealed three positive cell lines (Fig. 5). Thus, at least at this allele, a strong enhancer/pro-

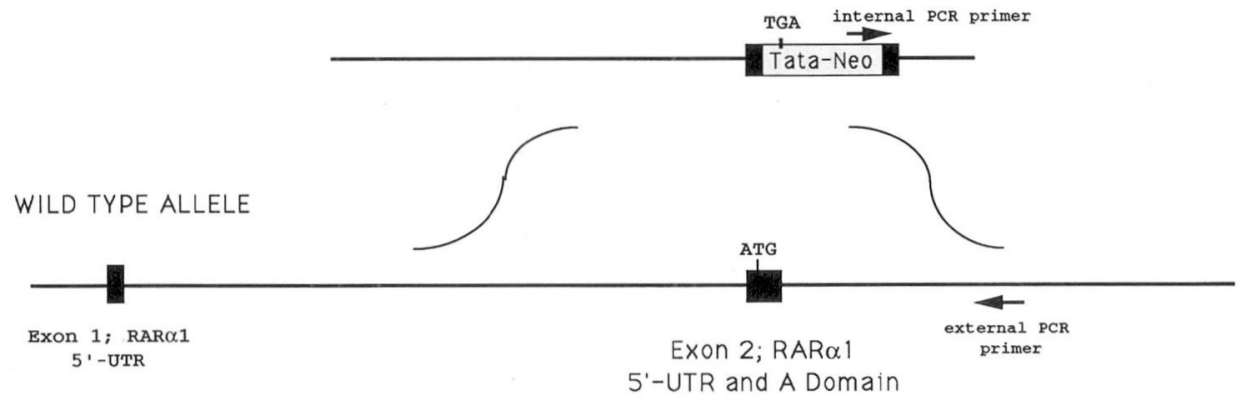

HOMOLOGOUS RECOMBINANT

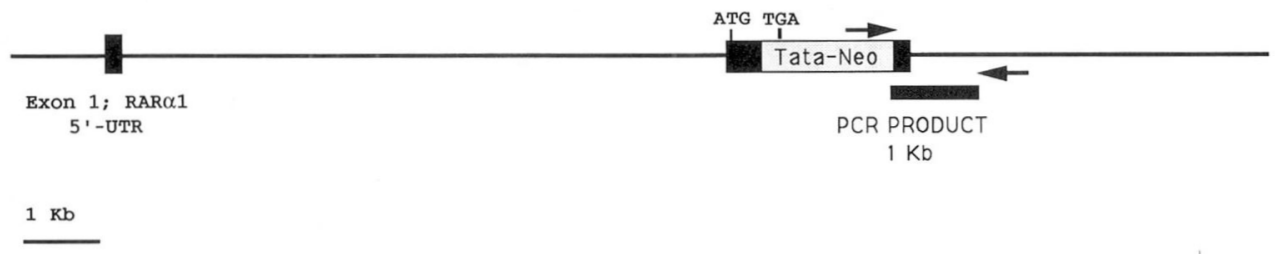

Fig. 4. Homologous recombination strategy for RAR $\alpha 1$. The targeting construct, target allele and predicted homologous recombinant are indicated. Exons are denoted as black boxes. The TGA within the Tata-neo cassette represents $5^{\prime}$ stop sites present upstream of the neo coding region. The AUG in exon two of the RAR $\alpha 1$ transcription unit represents the initiation codon for the RAR $\alpha 1$ protein. The location of PCR primers are noted by horizontal arrows, and the predicted PCR reaction product by a thick horizontal line. 


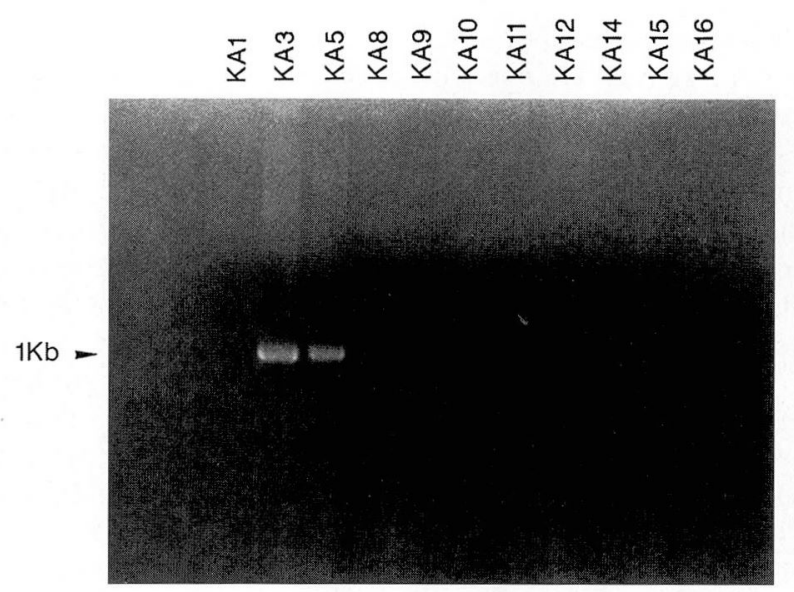

Fig. 5. PCR analysis for homologous recombination at the RAR $\alpha 1$ allele. Genomic DNA was isolated from ES cell colonies electroporated with the construct shown in Fig. 4. The per was carried out under standard conditions using primers as indicated in Fig. 4. A sample of each reaction was run on an agarose gel and stained with ethidium bromide. Two positive cell lines (KA3 and KA5) are shown in the figure. A third positive line (KA 26) is not indicated.

moter driving the expression of the neo gene is not necessary to obtain targeting events. These clones were expanded and injected into blastocysts to generate chimeras. All three clones gave chimeric males which passed the mutated allele to their offspring (Table 1). We have since inbred het-

Table 1. Germ line transmission of the RAR 1 null mutation

\begin{tabular}{|c|c|c|c|c|}
\hline Chimera & Clone & Offspring & $\begin{array}{c}\text { Number of } \\
\text { Agouti }\end{array}$ & $\begin{array}{c}\text { Genotype } \\
(+/-)\end{array}$ \\
\hline 1 & KA3 & 0 & 0 & \\
\hline 2 & KA3 & 20 & 18 & 7 \\
\hline 3 & KA3 & 0 & 0 & \\
\hline 4 & KA3 & 19 & 9 & 3 \\
\hline 5 & KA3 & 4 & 4 & 1 \\
\hline 6 & KA3 & 36 & 25 & 18 \\
\hline 7 & KA5 & 16 & 16 & 11 \\
\hline 8 & KA5 & 19 & 10 & 7 \\
\hline 9 & KA5 & 0 & 0 & \\
\hline 10 & KA5 & 0 & 0 & \\
\hline 11 & KA5 & 31 & 17 & 6 \\
\hline 12 & KA26 & 13 & 4 & 1 \\
\hline 13 & KA26 & 17 & 16 & 6 \\
\hline 14 & KA26 & 55 & 45 & 31 \\
\hline 15 & KA26 & 20 & 20 & 8 \\
\hline 16 & KA26 & 37 & 32 & 14 \\
\hline 17 & KA26 & 10 & 10 & 4 \\
\hline 18 & KA26 & 4 & 0 & \\
\hline 19 & KA26 & 3 & 3 & 1 \\
\hline 20 & KA26 & 9 & 0 & \\
\hline 21 & KA26 & 18 & 16 & 7 \\
\hline 22 & KA26 & 0 & 0 & \\
\hline
\end{tabular}

The positive ES clones identified by the pcr in Fig. 5 were injected into blastocysts and the resulting male chimeras bred with C57B $1 / 6$ females. Germ line transmission was initially scored by the presence of agouti coat colour. Pups carrying the mutated allele were identified by genomic Southern blot analysis of tail tip DNA. (+/-) indicates the number of heterozygote animals present among the agouti offspring. erozygote animals to generate homozygote mutant offspring, and are currently examining these animals for any phenotypic changes resulting from the loss of this gene product. It is important to note that recombination of this construct at the mRAR $\alpha 1$ locus has no measurable effect on the expression of the mRAR $\alpha 2$ gene (data not shown). The strategy of using a minimal promoter to express the neo gene may therefore be of general use for targeted disruption of genes which lie in proximity to other transcription units.

In analogous experiments, we have successfully targeted a number of mRARs and mRAR isoforms including mRAR $\alpha 1, m R A R \alpha$ (all isoforms), mRAR $\beta 2, \operatorname{mRAR} \beta$ (all isoforms), mRAR $\gamma 2, \operatorname{mRAR} \gamma$ (all isoforms). In addition, we have successfully disrupted the genes encoding mouse cellular retinoid-binding proteins CRABPI and II.

\section{Conclusions}

The ultimate interpretation of retinoid signalling at a cellular level is influenced by a large number of interactive gene products, including: (1) cellular retinoid-binding proteins, which may regulate the formation of active retinoids or control the cellular concentration of free ligand available to associate with retinoid receptors; (2) retinoid receptors which include at least two families, the three RARs and the three RXRs. These receptor families are composed of at least 11 different members (including isoforms), and are under a strict developmental expression program, as evidenced by their different spatio-temporal expression patterns in the developing mouse. An additional level of complexity with regard to control of retinoid-responsive target gene expression may be brought about through heterodimerization of RARs and RXRs to activate differentially, possibly in a cell-type and promoter-specific manner, subsets of these target genes. An additional consideration, not discussed here, is the regulation of retinoid biosynthesis. The enzymes controlling the production, and possibly the catabolism, of the various biologically active retinoids (eg. T-RA, 9C-RA and ddRA) may also play a pivotal role in this network.

In order to further investigate the role(s) that each of these genes play in murine development, we have sucessfully used gene targeting via homologous recombination in ES cells to create null mutants for a number of the key players in the retinoid signalling pathway. Subsequent analysis of the phenotypic changes brought about by these null mutations should give valuable insight as to the processes that are regulated by each of these proteins, and thus further our understanding of the function(s) performed by each member of this signalling pathway.

The authors would like to thank C. Werlé, B, Boulay, J. M. Lafontaine and the secretarial staff for help in the preparation of the manuscript. We also thank members of the cell culture and animal care facilities for their assistance. The D3 ES cell line was generously provided by Dr R. Kemler. This work was supported by grants from the CNRS, the INSERM, the Centre Hospitalier Universitaire Regionale, the Ministère de la Recherche et de la Technologie, the Fondation pour la Recherche Médicale and the Association pour la Recherche contre le Cancer. 


\section{References}

Beato, M. (1989). Gene regulation by steroid hormones. Cell 56, 335-344.

Benbrook, D., Lernhardt, E. and Pfahl, M. (1988). A new retinoic acid receptor identified from a hepatocellular carcinoma. Nature 333, 669672.

Blomhoff, R., Green, M. H., Berg, T. and Norum K. R. (1990). Transport and storage of vitamin A. Science 250, 399-404.

Blomhoff, R., Green, M. H., Berg, T. and Norum, K. R. (1991). Vitamin A metabolism: New perspectives on absorption, transport and storage. Physiol. Rev. 71, 952-990.

Blumberg, B., Mangelsdorf, D. J., Dyck, J. A., Bittner, D. A., Evans, R. M. and De Robertis, E. (1992). Multiple retinoid-responsive receptors in a single cell: families of RXRs and RARs in the Xenopus egg. Proc. Nat. Acad. Sci., USA 89, 2321-2325.

Bocquel, M. T., Kumar, V., Stricker, C., Chambon, P. and Gronemeyer, H. (1989). The contribution of the $\mathrm{N}$ - and $\mathrm{C}$ - terminal regions of steroid receptors to activation of transcription is both receptor and cell-specific Nucl. Acids Res. 17, 2581-2595.

Brand, N., Petkovich, M., Krust, A., Chambon, P., de Thé, H., Marchio, A., Tiollais, P. and Dejean, A. (1988). Identification of a second human retinoic acid receptor. Nature 332, 850-853.

Brand, N., Petkovich, M. and Chambon, P. (1990). Characterization of a functional promoter for the human retinoic acid receptor-alpha (hRAR-

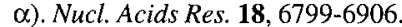

Brockes, J. (1989). Retinoids, homeobox genes and limb morphogenesis. Neuron 2, 1285-1294.

Brockes, J. (1990). Reading the retinoid signal. Nature 345, 766-768.

Brockes, J. (1991). We may not have a morphogen. Nature 350, 15.

Capecchi, M. R. (1989). Altering the genome by homologous recombination. Science 244, 1288-1292.

Chambon, P., Zelent, A., Petkovich, M., Mendelsohn, C., Leroy, P., Krust, A., Kastner, P. and Brand, N. (1991). In Retinoids: 10 Years On (ed. J.-H. Saurat), pp. 10-27. Basel, Switzerland: S. Karger.

Chytil, F. (1984). Retinoic acid: biochemistry, pharmacology, toxicology and therapeutic use. Pharmacol. Rev. 36, 93S-100S.

Chytil, F. and Haq, R. (1990). Vitamin A mediated gene expression. Critical Reviews in Eukaryotic Gene Expression 1, 61-73.

de Thé, H., Marchio, A., Tiollais, P. and Dejean, A. (1987). A novel steroid thyroid hormone receptor related gene inappropriately expressed in human hepatocellular carcinoma. Nature 330, 667-670.

de Thé, H., del Mar Vivanco-Ruiz, M., Tiollais, P., Stunnenberg, H., and Dejean, A. (1990). Identification of a retinoic acid responsive element in the retinoic acid receptor $\beta$ gene. Nature 343, 177-180.

Dollé, P., Ruberte, E., Kastner, P., Petkovich, M., Stoner, C. M., Gudas, L. J. and Chambon, P. (1989). Differential expression of the genes encoding the retinoic acid receptors $\alpha, \beta, \gamma$ and CRABP in the developing limbs of the mouse. Nature 342, 702-705.

Dollé, P., Ruberte, E., Leroy, P., Morris-Kay, G. and Chambon, P. (1990). Retinoic acid receptors and cellular retinoid-binding proteins. I. A systematic study of their differential pattern of transcription during mouse organogenesis. Development 110, 1133-1151.

Durand, B., Saunders, M., Leroy, P., Leid, M. and Chambon, P. (1992). All trans and 9-cis retinoic acid induction of mouse CRABP II gene transcription is mediated by RAR/RXR heterodimers. Cell 71, 73-85.

Eichele, G. (1989a). Retinoids and vertebrate limb pattern formation. Trends Genet. 5, 246-25I

Eichele, G. (1989b). Retinoic acid induces a pattern of digits in anterior half wing buds that lack the zone of polarizing activity. Development 107 , 863-867.

Evans, R. (1988). The steroid and thyroid hormone receptor family. Science 240, 889-895.

Fleischhauer, K., Park, J. H., DiSanto, J. P., Marks, M., Ozato, K. and Yang, S. Y. (1992). Isolation of a full-length cDNA clone encoding a Nterminally variant form of the human retinoid $\mathrm{X}$ receptor $\beta$. Nucl. Acids Res. 20, 1801.

Giguère, V., Ong, E. S., Segue, P. and Evans, R. M. (1987). Identification of a receptor for the morphogen retinoic acid. Nature 330, 624-629.

Giguère, V., Ong, E. S., Evans, R. M. and Tabin, C. J. (1989). Spatial and temporal expression of the retinoic acid receptor in the regenerating amphibian limb. Nature 337, 566-569.

Giguère, V., Lyn, S., Yip, P., Siu, C.-H. and Amin, S. (1990a). Molecular cloning of a cDNA encoding a second cellular retinoic acid-binding protein. Proc. Nat. Acad. Sci., USA 87, 6233-6237.
Giguère, V., Shago, M., Zirngibl, R., Tate, P., Rossant, J. and Varmuza, S. (1990b). Identification of a novel isoform of the retinoic acid receptor $\gamma$ expressed in the mouse embryo. Mol. Cell. Biol. 10, 2335-2340.

Green, S. and Chambon, P. (1988). Nuclear receptors enhance our understanding of transcription regulation. Trends Genet. 4, 309-314.

Hamada, K., Gleason, S. L., Levi, B.-Z., Hirschfeld, S., Apopela, E. and Ozato, K. (1989). H-2RIIBP, a member of the nuclear hormone receptor superfamily that binds to both the regulatory element of major histocompatibility class I genes and the estrogen response element. Proc. Nat, Acad. Sci., USA 86, 8289-8293.

Heyman, R. A., Mangelsdorf, D. J., Dyck, J. A., Stein, R., Eichele, G., Evans, R. M. and Thaller, C. (1992). 9-Cis retinoic acid is a high affinity ligand for the retinoid X receptor. Cell 68, 397-406.

Izpisua-Belmonte, J.-C., Tickle, C., Dollé, P., Wolpert, L. and Duboule, D. (1991). Expression of the homeobox Hox-4 genes and the specification of position in chick wing development. Nature 350, 585-589.

Ishikawa, T., Umesono, K., Mangelsdorf, D. J., Aburatani, H., Stanger, B. Z., Shibasaki, Y., Imawari, M., Evans, R. M. and Takaku, F. (1990). A functional retinoic acid receptor encoded by the gene on the human chromosome 12. Mol. Endocr. 4, 837-844.

Kastner, P., Krust, A., Mendelsohn, C., Garnier, J. M., Zelent, A., Leroy, P., Staub, A. and Chambon, P. (1990). Murine isoforms of retinoic acid receptor gamma with specific patterns of expression. Proc. Nat. Acad. Sci., USA 87, 2700-2704.

Kessel, M. and Gruss, P. (1991). Homeotic transformations of murine vertebrae and concomitant alteration of Hox codes induced by retinoic acid. Cell 67, 89-104.

Kliewer, S. A., Umesono, K., Mangelsdorf, D. J. and Evans, R. M. (1992). The retinoid X receptor interacts directly with nuclear receptors involved in retinoic acid, thyroid hormone and vitamin $D_{3}$ signaling. Nature 355, 446-449.

Krust, A., Kastner, P., Petkovich, M., Zelent, A. and Chambon, P. (1989). A third human retinoic acid receptor, hRAR- $\gamma$. Proc. Nat. Acad. Sci., USA 85, 329-333.

LaRosa, G. J. and Gudas, L. J. (1988). An early effect of retinoic acid: cloning of an mRNA (Era-I) exhibiting rapid and protein synthesisindependent induction during teratocarcinoma stem cell differentiation. Proc. Nat. Acad. Sci., USA 85, 329-333.

Lehmann, J. M., Zhang, X.-K. and Pfahl, M. (1992). RAR $\gamma 2$ expression is regulated through a retinoic acid response element embedded in Sp1 sites. Mol. Cell. Biol. 12, 2976-2985.

Leid, M., Kastner, P., Lyons, R., Nakshatri, H., Saunders, M., Zacharewski, T., Chen, J.-Y., Staub, A., Garnier, J.-M., Mader, S. and Chambon, P. (1992). Purification, cloning and RXR identity of the HeLa cell factor with which RAR or TR heterodimerizes to bind target sequences efficiently. Cell 68, 377-395.

Leroy, P., Krust, A., Zelent, A., Mendelsohn, C., Garnier, J. M., Kastner, P., Dierich, A. and Chambon, P. (1991a). Multiple isoforms of the mouse retinoic acid receptor alpha are generated by alternative splicing and differential induction by retinoic acid. ЕMBO J. 10,5969.

Leroy, P., Nakshatri, H. and Chambon, P. (1991b). The mouse retinoic acid receptor alpha-2 (mRAR- $\alpha 2)$ isoform is transcribed from a promoter that contains a retinoic acid response element. Proc. Nat. Acad. Sci., USA 88, 10138-10142.

Levin, M. S., Li, E., Ong, D. E. and Gordon, J. I. (1987). Comparison of the tissue-specific expression and developmental regulation of two closely linked rodent genes encoding cytosolic retinol-binding proteins. J. Biol. Chem. 262, 7118-7124

Levin, A. A., Sturzenbecker, L. M., Kazmer, S., Bosakowski, T., Huselton, C., Allenby, G., Speck, J., Kratzeisen, C. Rosenberger, M., Lovey, A. and Grippo, J. F. (1992). 9-cis retinoic acid sterioisomer binds and activates the nuclear receptor RXR $\alpha$, Nature 355, 359-361

Lufkin, T., Dierich, A., LeMeur, M., Mark, M. and Chambon, P. (1991). Disruption of the Hox-1.6 homeobox gene results in defects in a region corresponding to its rostral domain of expression. Cell 66, 1105-1119.

Maden, M. (1982). Vitamin A and pattern formation in the regenerating limb. Nature 295, 672-675.

Maden, M. (1985). Retinoids and the control of pattern in limb development and regeneration. Trends Genet. 1, 103-107.

Maden, M., Ong, D. E., Summerbell, D. and Chytil, F. (1988). Spatial distribution of cellular proteins binding to retinoic acid in the chick limb bud. Nature 335, 733-735.

Mangelsdorf, D. J., Ong, E. S., Dyck, J. A. and Evans, R. M. (1990) 
Nuclear receptor that identifies a novel retinoic acid response pathway. Nature 345, 224-229.

Mangelsdorf, D. J., Umesono, D., Kliewer, S. A., Borgmeyer, U., Ong, E. S. and Evans, R. M. (1991). A direct repeat in the cellular retinol-binding protein type II gene confers differential regulation by RXR and RAR. Cell 66, 555-561.

Mangelsdorf, D. J., Borgmeyer, U., Heyman, R. A., Zhou, J. Y., Ong, E. S., Oro, A. E., Kakizuka, A. and Evans, R. M. (1992). Characterization of the three RXR genes that mediate the action of 9-cis retinoic acid. Genes Dev. 6, 329-344.

Mattei, M.-G., Riviere, M., Krust, A., Ingvarsson, S., Venstrom, B. Islam M. Q., Levan, G., Kastner, P., Zelent, A., Chambon, P., Szpierer, J. and Szpierer, C. (1991). Chromosomal assignment of retinoic acid receptor (RAR) genes in the human, mouse and rat genomes. Genomics 10, 1061-1069.

Mendelsohn, C., Ruberte, E., LeMeur, M., Morriss-Kay, G. and Chambon, P. (1991). Developmental analysis of the retinoic acidinducible RAR- 32 promoter in transgenic animals. Development 113, 723-734

Moore, D. D. (1990). Diversity and unity in the nuclear hormone receptors: a terpenoid receptor superfamily. The New Biologist 2, 100-105.

Murphy, S. P., Garbern, J., Odenwald, W. F., Lazzarini, R. A. and Linney, E. (1988). Differential expression of the homeobox gene Hox-1. 3 in F9 embryonal carcinoma cells. Proc. Nat. Acad. Sci., USA 85, 55875591.

Nagpal, S., Zelent, A. and Chambon, P. (1992a). RAR- $\beta 4$, a retinoic acid receptor isoform is generated from RAR- $\beta 2$ by alternative splicing and usage of a CUG initiator codon. Proc. Nat. Acad. Sci., USA 89, 27182722.

Nagpal, S., Saunders, M., Kastner, P., Durand, B., Nakshatri, H. and Chambon, P. (1992b). Differential promoter-context and response element-dependent specificity of the trans acting and modulating functions of the multiple nuclear retinoid receptors (RARs and RXRs) Cell 70, 1007-1013.

Nicholson, R. C., Mader, S., Nagpal, S., Leid, M., Rochette-Egly, C. and Chambon, P. (1990). Negative regulation of the rat stromelysin gene promotor by retinoic acid is mediated by an API binding site. EMBO J.9, 4443-4454.

Noji, S., Nohno, T., Koyama, E., Muto, K., Ohyama, K., Aoki, Y., Tamura, K., Ohsugi, K., Ide, H., Taniguchi, S. and Saito, T. (1991) Retinoic acid induces polarizing activity but is unlikely to be a morphogen in the chick limb bud. Nature 350, 83-86.

Ong, D. E. (1987). Cellular retinoid binding proteins. Arch. Dermatol. 123 , 1693a-1695a.

Ong, D. E., Kakkad, B. and MacDonald, P. N. (1987). Acetyl-CoAindependent esterification of retinol bound to a cellular retinol-binding protein (type II) by microsomes from rat small intestine. J. Biol. Chem. 262, 2729-2736.

Oro, A. E., McKeown, M. and Evans, R. M. (1990). Relationship between the product of the Drosophila ultraspiracle locus and the vertebrate retinoid X receptor. Nature 347, 298-301.

Petkovich, M., Brand, N. J., Krust, A. and Chambon, P. (1987). A human retinoic acid receptor which belongs to the family of nuclear receptors. Nature 330, 444-450.

Ragsdale Jr, C. W., Petkovich, M., Gates, P. B., Chambon, P. and Brockes, J. P. (1989). Identification of a novel retinoic acid receptor in regenerative tissues of the newt. Nature 341, 654-657.

Ragsdale Jr, C. W. and Brockes, J. P. (1991). Retinoic acid receptors and vertebrate limb morphogenesis. In Structure and Function of Hormone Nuclear Receptors, (ed. M. G. Parker), pp. 269-295. London: Academic Press.

Rowe, A., Eager, N. S. C. and Brickell, P. M. (1991). A member of the RXR nuclear receptor family is expressed in neural-crest-derived cells of the developing peripheral nervous system. Development 111, 771-778.

Ruberte, E., Dollé, P., Krust, A., Zelent, A., Morriss-Kay, G. and Chambon, P. (1990). Specific spatial and temporal distribution of retinoic acid receptor gamma transcripts during mouse embryogenesis. Development 108, 213-222.

Ruberte, E., Dollé, P., Chambon, P. and Morriss-Kay, G. (1991) Retinoic acid receptors and cellular retinoid binding proteins: II. Their differential pattern of transcription during early morphogenesis in mouse embryos. Development 111, 45-60.
Simeone, A., Acampora, D., Arcioni, L., Andrews, P. W., Boncinelli, E. and Mavilio, F. (1990). Sequential activation of HOX2 homeobox genes by retinoic acid in human embryonal carcinoma cells. Nature 346, 763766.

Slack, J. M. (1987). We have a morphogen. Nature 327, 553-554.

Smith, S. M. and Eichele, G. (1991). Temporal and regional difference in the expression pattern of distinct retinoic acid receptor- $\beta$ transcripts in the chick embryo. Development 111, 245-252.

Smith, S. M., Pang, K., Sundin, O., Wedden, S. E., Thaller, C. and Eichele, G. (1989). Molecular approaches to vertebrate limb morphogenesis. Development 107 Supplement, 121-131.

Smith, W. C., Nakshatri, H., Leroy, P., Rees, J. and Chambon, P. (1991). A retinoic acid response element is present in the mouse cellular retinol binding protein I (mCRBP I) promoter. EMBO J, 10, 2223-2230.

Stoner, C. M. and Gudas, L. J. (1989). Mouse cellular retinoic acid binding protein: cloning, complementary DNA sequence and messenger RNA expression during the retinoic acid induced differentiation of $F 9$ wild type and RA-3-10 mutant teratocarcinoma cells. Cancer Res. 49, 1497-1504

Sucov, H. M., Murakame, K. K. and Evans, R. M. (1990) Characterization of an autoregulated response element in the mouse retinoic acid receptor type $\beta$ gene. Proc. Nat. Acad. Sci., USA 87, 53925396.

Takase, S., Ong, D. E. and Chytil, F. (1979). Cellular retinol-binding protein allows specific interaction of retinol with the nucleus in vitro. Proc. Nat. Acad. Sci., USA 76, 2204-2220.

Takase, S., Ong, D. E. and Chytil, F. (1986). Transfer of RA from its complex with cellular retinoic acid binding protein to the nucleus. Arch Biochem. Biophys. 247, 328 .

Thaller, C. and Eichele, G. (1987). Identification and spatial distribution of retinoids in the developing chick limb bud. Nature 327, 625-628.

Thaller, C. and Eichele, G. (1990). Isolation of 3, 4-didehydroretinoic acid, a novel morphogenetic signal in the chick wing bud. Nature $345,815-$ 819.

Tickle, C., Alberts, B., Wolpert, L. and Lee, J. (1982). Local application of retinoic acid to the limb bud mimics the action of the polarizing region. Nature 296, 564-566.

Tora, L., Gaub, M.-P., Mader, S., Dierich, A., Bellard, M. and Chambon, P. (1989). The human estrogen receptor has two independent nonacidic transcriptional activation functions. Cell 59, 477-487.

Wanek, N., Gardiner, D. M., Muneoka, K. and Bryant, S. V. (1991). Conversion by retinoic acid of anterior cells into ZPA cells in the chick wing bud. Nature 350, 81-83.

Wang, S.-Y. and Gudas, L. J. (1983). Isolation of cDNA clones specific for collagen IV and laminin from mouse teratocarcinoma cells. Proc. Nat. Acad. Sci., USA 80, 5880-5884.

Wang, C., Kelly, J., Bowden-Pope, D. F. and Stiles, C. D. (1990) Retinoic acid promotes transcription of the PDGF $\alpha$-receptor gene. Mol. Cell. Biol. 10, 6781-6784.

Webster, N. J. G., Green, S., Jin, J. R. and Chambon, P. (1988). The hormone-binding domains of the estrogen and glucocorticoid receptors contain an inducible transcription activation function. Cell 54, 199207.

Wei, L.-N., Blaner, W. S., Goodman, D. S. and Nguyen-Huu, M. C. (1989). Regulation of the cellular retinoid-binding proteins and their messenger ribonucleic acids during P-19 embryonal carcinoma cell differentiation induced by retinoic acid. Mol. Endocrinol. 3, 454-463.

Yu, V. C., Delsert, C., Andersen, B., Holloway, J. M., Devary, O., Nar, A. M., Kim, S. Y., Boutin, J.-M., Glass, C. K. and Rosenfeld, M. G. (1991). RXR- $\beta$ : a coregulator that enhances binding of retinoic acid, thyroid hormone and vitamin $\mathrm{D}$ receptors to their cognate response elements. Cell 67, 1251-1266.

Zelent, A., Krust, A., Petkovich, M., Kastner, P. and Chambon, P. (1989). Cloning of murine $\alpha$ and $\beta$ retinoic acid receptors and a novel receptor $\gamma$ predominantly expressed in skin. Nature 339, 714-717.

Zelent, A., Mendelsohn, C., Kastner, P., Garnier, J. M., Ruffenach, F., Leroy, P. and Chambon, P. (1991). Differentially expressed isoforms of the mouse retinoic acid receptor beta are generated by usage of two promoters and alternative splicing. EMBO J. 10, 71-81.

Zhang, X.-K., Hoffmann, B., Tran, P. B.-V., Graupner, G. and Pfahl, M. (1992). Retinoic X receptor is an auxiliary protein for thyroid hormone and retinoic acid receptors. Nature $\mathbf{3 5 5}, 441-446$. 